\title{
Spectrograph dedicated to measuring tropospheric trace gas constituents from space
}

\author{
Johan de Vries ${ }^{*{ }^{\mathrm{a}} 1}$, Erik C. Laan ${ }^{\mathrm{a}}$, Alex F. Deutz ${ }^{\mathrm{a}}$, Isabel Escudero-Sanz ${ }^{\mathrm{b}}$, Henk Bokhove ${ }^{\mathrm{b}}$, Jan \\ Hoegee $^{\mathrm{b}}$, Ilse Aben ${ }^{\mathrm{c}}$, Rienk Jongma ${ }^{\mathrm{c}}$, Jochen Landgraf ${ }^{\mathrm{c}}$, Otto P.Hasekamp ${ }^{\mathrm{c}}$, Sander Houweling ${ }^{\mathrm{c}}$, \\ Michiel van Weele ${ }^{\mathrm{d}}$, Roeland van Oss ${ }^{\mathrm{d}}$, Gijsbertus van den Oord ${ }^{\mathrm{d}}$, Pieternel Levelt ${ }^{\mathrm{d}}$ \\ ${ }^{a}$ Dutch Space BV, Newtonweg 1, 2333 CP Leiden, The Netherlands \\ ${ }^{\mathrm{b}}$ TNO Industrie en Techniek, Stieltjesweg 1, 2628 CK, Delft, The Netherlands \\ ${ }^{\mathrm{c}}$ Netherlands Institute for Space Research (SRON), Sorbonnelaan 2, 3584 CA Utrecht, The \\ Netherlands \\ ${ }^{\mathrm{d}}$ Royal Netherlands Meteorological Institute (KNMI), Wilhelminalaan 10, 3732 GK De Bilt, The \\ Netherlands
}

\begin{abstract}
Several organizations in the Netherlands are cooperating to develop user requirements and instrument concepts in the line of SCIAMACHY and OMI but with an increased focus on measuring tropospheric constituents from space. The concepts use passive spectroscopy in dedicated wavelength sections in the range of 300 to $2400 \mathrm{~nm}$ and wide angle, nonscanning, swath viewing.

To be able to penetrate into the troposphere small ground pixels are used to obtain a fair fraction of cloud-free pixels and to allow precise detection of the sources of polluting gases.

The trace gas products aimed for are $\mathrm{O}_{3}, \mathrm{NO}_{2}, \mathrm{HCHO}, \mathrm{H}_{2} \mathrm{O}, \mathrm{SO}_{2}$, Aerosol (optical depth, type and absorption index), $\mathrm{CO}$ and $\mathrm{CH}_{4}$, covering science issues on air quality and climate.

The main challenge in the instrument design is to obtain a good signal-to-noise for cloud free pixels and for low ground albedo and light levels. Also the retrieval of separated tropospheric and stratospheric column amounts from a nadir looking instrument is challenging.

The paper discusses the user requirements and compares alternative measurement strategies. It explains the selection of passive UV-Visible-NIR spectroscopy and comes with an instrument concept which provides the current best realisation of the user requirements.
\end{abstract}

Keywords: UV-Visible NIR spectrograph, trace gas monitoring, tropospheric constituents

\section{INTRODUCTION}

This paper discusses a concept for a new satellite instrument for global observations of atmospheric composition. The concept is driven by the need of users for improved information on global-scale air quality and the interactions between atmospheric composition and climate. The user community is firstly scientific, but the instrument also serves users in a wider community, i.e. from environmental policy support and supporting the international frameworks for sustained and comprehensive long-term monitoring (IGACO, 2004; GEOSS, 2004)

The concept is based on the experience that has been gained in the Netherlands and some other countries in recent years. Since the mid-1980s the Dutch science community has been increasingly involved in satellite remote sensing of atmospheric composition. Since that time, scientists and industry have contributed substantially to designing, building, processing and analysing data of the instruments GOME (launched in 1995 on ESA's ERS2 satellite), SCIAMACHY

1 j.de.vries@dutchspace.nl; phone +31 5245879; fax +31 5245835; P.O. Box 32070, 2303 DB Leiden, the Netherlands

Sensors, Systems, and Next-Generation Satellites IX, edited by Roland Meynart, Steven P. Neeck, Haruhisa Shimoda, Proc. of SPIE Vol. 5978, 597800, (2005) · 0277-786X/05/\$15 - doi: 10.1117/12.627008 
(launched in 2002 on ESA's ENVISAT) and OMI (launched in 2004 on NASA's AURA). In particular, this has been substantiated by a co-PI contribution to SCIAMACHY and a PI contribution to OMI. The working name of the current instrument concept is TROPOMI, from 'TROPospheric OMI'.

GOME, SCIAMACHY and OMI were driven primarily by concerns about degradation of the stratospheric ozone layer. In addition, however, successful efforts were made to retrieve a suite of tropospheric parameters including trace gases, aerosols and cloud information. Each successive instrument had a higher spatial resolution, providing more useful information on tropospheric composition. The new concept aims to continue this sequence and fits well in the Dutch Space Strategy for the period 2002-2010.

The UV-Visible part of the TROPOMI has been used in the TRAQ (TRopospheric composition and Air Quality) proposal to ESA's Call for Earth Explorer Ideas, 2005 and the full concept has been used in the CAMEO (Composition of the Atmosphere from Mid-Earth Orbit) proposal to the January 2005 request for information by the U.S. National Research Council Decadal Study on 'Earth Science and Applications from Space'.

\section{SCIENCE OBJECTIVES}

The concept aims at measuring the main tropospheric gaseous pollutants $\left(\mathrm{O}_{3}, \mathrm{NO}_{2}, \mathrm{CO}, \mathrm{CH}_{2} \mathrm{O}\right.$ and $\left.\mathrm{SO}_{2}\right)$ and two major climate gases (tropospheric $\mathrm{O}_{3}$ and $\mathrm{CH}_{4}$ ). $\mathrm{CO}$ is relevant to climate as a precursor gas for $\mathrm{CO}_{2}$ and, together with $\mathrm{NO}_{2}$ and $\mathrm{CH}_{2} \mathrm{O}$, for tropospheric $\mathrm{O}_{3}$. In addition, the mission aims at measuring aerosols, which play a key role in tropospheric pollution as well as in climate change. Especially the UV Aerosol Optical Depth contributes uniquely to the available satellite-based aerosol measurements. The continuation of the $\mathrm{CH}_{4}$ and $\mathrm{CO}$ measurements started by SCIAMACHY is also very important for obtaining a long satellite record for climate research.

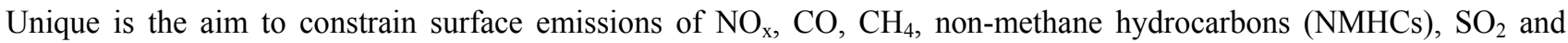
aerosols. Although many attempts have been made to obtain such surface emissions by inverse modelling using the currently available satellite measurements, none of these missions have originally set out their requirements on obtaining surface emissions. The lacking insight in emission patterns and their trend and variability is actually one of the major uncertainties in atmospheric and climate modelling today (IPCC TAR: Houghton et al). Better constraints on surface emissions will enable better determination of the impact of anthropogenic activities on the global atmosphere during the mission lifetime.

Another specific objective is the study of long-range transport of pollutants. This instrument intends to measure freetropospheric transport of tropospheric ozone, $\mathrm{CO}$ and aerosols in particular over low clouds using the increased reflection. Furthermore, the detection of $\mathrm{NO}_{2}$ over thick (convective) clouds will enable to better constrain $\mathrm{NO}_{\mathrm{x}}$ production by lighting flashes. Last but not least the instrument intends to prove that operational monitoring of air pollution is possible and can facilitate air pollution forecasts up to five days ahead.

The instrument will complement the monitoring that has been initiated by earlier missions. Specifically, it will be adequately designed to continue the record of total ozone columns since 1979 that has been constructed based on the NASA TOMS instrument series and, since 2004, on the Dutch-Finnish OMI instrument; the records of tropospheric $\mathrm{NO}_{2}$, $\mathrm{O}_{3}, \mathrm{H}_{2} \mathrm{O}, \mathrm{CH}_{2} \mathrm{O}, \mathrm{SO}_{2}$, surface UV and aerosol products since 1995 based on the GOME, Sciamachy and OMI series of instruments; and the records $\mathrm{CO}$ and $\mathrm{CH}_{4}$ based on MOPITT (since 1999) and Sciamachy (since 2002).

\section{RELATION TO OTHER SATELLITE INSTRUMENTS}

For the target launch time of 2010-2012 the MetOp and NPOESS Programs each have atmospheric instruments in space, including, respectively, GOME-2, IASI, AVHRR and OMPS, among others. These instruments all make great contributions to atmospheric monitoring, but are limited in their capacities for Air Quality and surface emissions due to their relative large ground pixel sizes and/or incomplete spectral ranges. Compared to GOME-2 and OMPS the spatial resolution of this new mission (baseline $8 \times 8 \mathrm{~km}^{2}$ ) will be unprecedented and it will provide daily insight in tropospheric 
pollution, based on the enormous increase in cloud-free pixels. The envisioned near-infrared spectral range is covered neither by MetOp nor NPOESS.

Depending on accompanying instruments on the same satellite, the instrument may use the MetOp/GOME-2 and NPOESS/OMPS ozone profiles for obtaining the stratospheric ozone columns that are to be subtracted from the (measured) total ozone columns to retrieve tropospheric ozone. In the case of the TRAQ proposal, atmospheric light path corrections are performed using data from the accompanying OCAPI instrument.

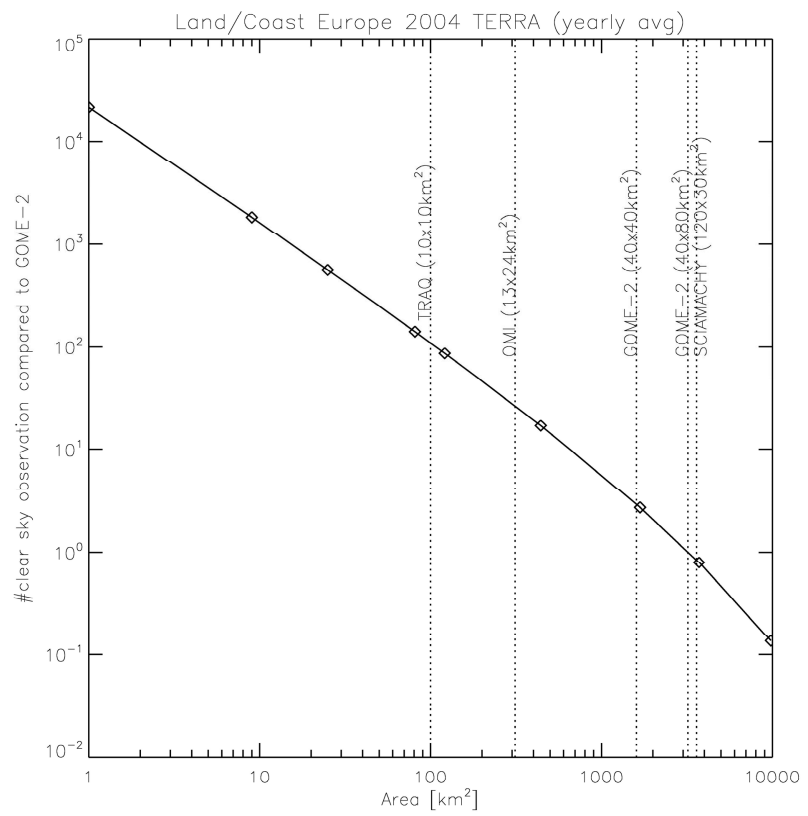

Figure 1 The overall gain factor in cloud-free observations for the TROPOMI/TRAQ pixel size is 109 (Europe over land) in comparison to GOME-2, and 260 (Europe over land) in comparison with SCIAMACHY, assuming identical swaths [Krijger et al., 2005]. This implies roughly that with the TROPOMI pixel sizes the sampling in one to three days corresponds with what can be achieved with GOME-2 and SCIAMACHY in one year. If we allow for $20 \%$ cloud-cover, which is still considered useful for tropospheric $\mathrm{NO}_{2}$ retrievals [Boersma et al., JGR, 2004], as many tropospheric observations are obtained within one day as GOME-2 will achieve in one month.

\section{DATA PRODUCT SPECIFICATIONS}

TROPOMI is a nadir viewing imaging spectrometer with a spectral resolution of $0.45 \mathrm{~nm}$ and a spectral sampling distance of $0.15 \mathrm{~nm}$, for wavelengths $>310 \mathrm{~nm}$. Column densities of trace gases $\left(\mathrm{NO}_{2}, \mathrm{O}_{3}, \mathrm{SO}_{2}\right.$, and $\left.\mathrm{HCHO}\right)$ will be derived using primarily the Differential Optical Absorption Spectroscopy (DOAS) method. The spectral windows and algorithms used are essentially the same as those used for OMI-Aura (see http://www.knmi.nl/omi/research/documents for the OMI ATBD). The uncertainty of the derived columns depends on the signal-to-noise ratio $(\mathrm{S} / \mathrm{N})$ and on the air mass factor (AMF). The AMF is the number of trace gas molecules encountered along an average light path relative to the total column and depends on the scenario considered. 
In order to arrive at $\mathrm{O}_{3}$ and $\mathrm{NO}_{2}$ tropospheric columns from the DOAS slant columns, first the stratospheric contribution to the slant columns needs to be estimated. For $\mathrm{NO}_{2}$, this is achieved by assimilating slant columns into a chemistry transport model for regions with negligible tropospheric $\mathrm{NO}_{2}$, i.e., over remote oceans. For $\mathrm{O}_{3}$, the stratospheric contribution is derived from assimilated TROPOMI ozone profiles. Then, the stratospheric contribution is subtracted from the slant column, and the residue is divided by the tropospheric AMF.

The uncertainties in the TROPOMI trace gas products have been estimated for a nominal and a minimum scenario. For the nominal scenario an average viewing geometry was selected with a geometrical AMF of 3 and a fairly large S/N of $2000-1500$ (some clouds present in the pixel). For the minimum scenario the geometrical AMF is 2, corresponding to a nadir view in the tropics, and the $\mathrm{S} / \mathrm{N}$ is $1500-1000$ (cloud-free pixels). The assumed surface albedo is 0.02 (dark, effectively a lower limit) in both scenarios.

Table 1 shows the data products with accuracies foreseen for the instrument. The table shows the TROPOMI 'module' from which the products are derived. This has been introduced because the TROPOMI design makes use of separate UVVisible-NIR and SWIR optical benches (or 'modules') for the respective wavelength ranges to allow flexibility in implementing the different thermal requirements.

\begin{tabular}{|c|c|c|c|c|}
\hline $\begin{array}{l}\text { Key } \\
\text { Observables }\end{array}$ & Product Type & Module & \multicolumn{2}{|c|}{$\begin{array}{cc}\text { Uncertainty, } & \text { relative numbers } \\
\text { nominal } & \text { minimum }\end{array}$} \\
\hline \multirow[t]{2}{*}{$\mathrm{NO}_{2}$} & Total Column & UV-Visible-NIR & $2 \%$ & $3 \%$ \\
\hline & Tropospheric Column & UV-Visible-NIR & $6 \%$ & $13 \%$ \\
\hline \multirow[t]{2}{*}{$\mathbf{O}_{3}$} & Total Column & UV-Visible-NIR & $0.5 \%$ & $2 \%$ \\
\hline & Tropospheric Column & UV-Visible-NIR & $15 \%$ & $35 \%$ \\
\hline $\mathrm{CO}$ & Total Column $^{1)}$ & SWIR & $6 \%$ & $19 \%$ \\
\hline $\mathrm{SO}_{2}$ & Total Column $^{1)}$ & UV-Visible-NIR & $5 \%$ & $10 \%$ \\
\hline HCHO & Total Column ${ }^{1)}$ & UV-Visible-NIR & $25 \%$ & $55 \%$ \\
\hline \multirow[t]{2}{*}{$\mathrm{CH}_{4}$} & Total Column ${ }^{1)}$ & SWIR & $0.1 \%$ & $0.5 \%$ \\
\hline & & & \multicolumn{2}{|c|}{ Accuracy } \\
\hline \multirow[t]{3}{*}{ Aerosol } & Aerosol Optical Thickness & UV-Visible-NIR & \multicolumn{2}{|c|}{$15 \%$} \\
\hline & Single scattering albedo & UV-Visible-NIR & \multicolumn{2}{|c|}{0.05} \\
\hline & Aerosol absorption index & UV-Visible-NIR & \multicolumn{2}{|c|}{$1 \%$} \\
\hline
\end{tabular}

Table 1 TROPOMI performances for total and tropospheric column retrievals under cloud-free conditions. Uncertainty refers to the relative uncertainties related to instrument $\mathrm{S} / \mathrm{N}$. The uncertainties pertain to the following column densities for $\mathrm{NO}_{2}, \mathrm{SO}_{2}, \mathrm{HCHO}, \mathrm{CO}$ and $\mathrm{CH}_{4}$ respectively: $5 \times 10^{15}, 4 \times 10^{16}, 4 \times 10^{16}, 1 \times 10^{18}$ and $3.8 \times 10^{19}\left[\mathrm{molecule} / \mathrm{cm}^{2}\right]$. The total column is $300 \mathrm{DU}$ and the tropospheric column is $20 \mathrm{DU}$ for $\mathrm{O}_{3}$. Accuracies are discussed in the text, but are given here for the aerosol products because uncertainties, which are related to $\mathrm{S} / \mathrm{N}$, are not the driving factor. Notes:

1) The total column is about equal to the tropospheric column for $\mathrm{CO}, \mathrm{HCHO}, \mathrm{CH}_{4}$, and $\mathrm{SO}_{2}$. $\mathrm{For}_{\mathrm{SO}_{2}}$ there is a stratospheric contribution during short periods after volcanic eruptions.

Except for the total $\mathrm{O}_{3}$ and $\mathrm{NO}_{2}$ column product, the $\mathrm{AMF}$ is taken to be one fourth of the geometrical AMF, because only those photons that penetrate deep into the troposphere and travel back to the sensor carry information on the troposphere. For moderate pollution, the accuracy of the tropospheric columns of $\mathrm{NO}_{2}, \mathrm{O}_{3}, \mathrm{SO}_{2}$, and $\mathrm{HCHO}$ is estimated to be $15 \%-25 \%, 20 \%$ $-40 \%, 30 \%-40 \%$, and $30 \%-60 \%$, respectively. Here the first number refers to the nominal and the second number to the minimum scenario. The accuracies include the uncertainty related to random instrument noise (Table 1) and all other errors, e.g. profile assumptions in case of profile retrieval and systematic instrument effects. The dominant uncertainty, caused by the AMF, will be improved in the future.

\section{CLOUD, AEROSOL AND SURFACE CHARACTERIZATION}

Absorbing trace gases inside or below a cloud are hardly visible for TROPOMI. In contrast, trace gases above the cloud are easily detected. Accurate (tropospheric) columns can therefore only be obtained if clouds are well characterized. Cloud correction algorithms for GOME and SCIAMACHY are usually based on observations of the $\mathrm{O}_{2} \mathrm{~A}$ band. For OMI on Aura two algorithms have been developed, one based on rotational Raman scattering and one based on the collisional induced absorption by $\mathrm{O}_{2}-\mathrm{O}_{2}$, mainly because the $\mathrm{O}_{2}$ A band is not observed. At present, these algorithms generally assume that the cloud is optically thick and that the surface albedo can be taken from a surface albedo climatology. These assumptions result in large errors $(35 \%-60 \%)$ for tropospheric columns of $\mathrm{NO}_{2}$. For a tropospheric mission, a new approach is required for surface and cloud characterization, such that the values of the surface albedo, the cloud optical 
thickness, cloud fraction, and cloud pressure can directly be determined from the measured spectrum itself. Then the AMF, used in DOAS, can be calculated accurately. For this reason, the $\mathrm{O}_{2} \mathrm{~A}$ band is included in TROPOMI, eliminating the currently largest sources of error for tropospheric columns. Initial test calculations are promising and it is expected that the errors due to uncertainties in the AMF can be reduced by a factor of 2-3.

Aerosol particles scatter and absorb solar radiation, and affect the average light path in the atmosphere and therefore the AMF. If aerosols are not taken into account, the typical errors for $\mathrm{CH}_{4}$ and $\mathrm{CO}$ are a few percent, which is not problematic for $\mathrm{CO}$, but too large for $\mathrm{CH}_{4}$. Errors in the tropospheric columns of $\mathrm{NO}_{2}, \mathrm{O}_{3}, \mathrm{SO}_{2}$, and $\mathrm{HCHO}$ are in the order of $10 \%-20 \%$, and may even be larger for elevated layers of absorbing aerosol. For the TRAQ mission, the OCAPI instrument, in combination with the TROPOMI $\mathrm{O}_{2} \mathrm{~A}$ band (aerosol height distribution) and the TROPOMI UV aerosol product (UV absorbing aerosol) will deliver the aerosol parameters required to improve the calculation of the AMF. Combining the information from different instruments will further reduce the errors.

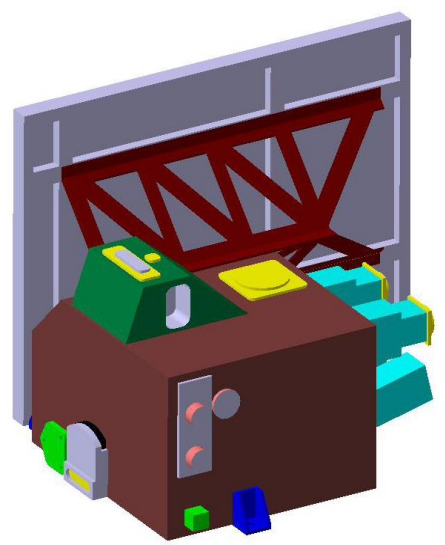

Figure 2 UV-Visible-NIR module of the TROPOMI instrument

\section{TROPOMI INSTRUMENT CONCEPT}

Based on the above, it is possible to conceptually define the TROPOMI (Tropospheric OMI). It is a five-channel nonscanning nadir viewing imaging spectrometer that combines a wide swath with high spatial resolution. The instrument design, by TNO and Dutch Space in the Netherlands, has a strong heritage from both the OMI instrument on the NASA's AURA mission ${ }^{1}$ and the Sciamachy on ESA's ENVISAT satellite.

Table 4 shows the wavelength bands and spatial definitions for the TROPOMI. The first channel, the UV1, is meant to have an $\mathrm{O}_{3}$ sounding with a typical vertical resolution of 5 to $8 \mathrm{~km}$. For this channel it is not necessary to have small ground pixels or Nyquist reconstructable continuous spectra and therefore the sampling distances in both spectral and spatial directions have been increased with a factor 4 as compared to the other channels. The spectral sampling is therefore about equal to the spectra resolution and this has the important advantage that the signal-to-noises can be reasonable in view of the low light levels at those wavelengths. 


\begin{tabular}{|c|c|c|c|c|}
\hline Channel & Spectral band & Signal-to-noise & Products & Sampling and resolution \\
\hline UV1 & $270-310 \mathrm{~nm}$ & $\begin{array}{l}100(\text { at } 270 \mathrm{~nm})- \\
1000(\text { at } 310 \mathrm{~nm})\end{array}$ & $\mathrm{O}_{3}$ sounding & $\begin{array}{l}\text { Spectral sampling/resolution: } 1.2 \mathrm{~nm} \\
\text { Swath: } 2600 \mathrm{~km} / 114^{\circ} . \\
\text { Spatial sampling: } 36 \mathrm{~km}\end{array}$ \\
\hline UV2 & $310-400 \mathrm{~nm}$ & 1000 & $\mathrm{O}_{3}, \mathrm{SO}_{2}, \mathrm{HCHO}$ & \multirow{3}{*}{$\begin{array}{l}\text { Spectral resolution: } 0.45 \mathrm{~nm} \\
\text { Spectral sampling: } 0.15 \mathrm{~nm} \\
\text { Swath: } 2600 \mathrm{~km} / 114^{\circ} \\
\text { Spatial sampling: } 8 \mathrm{~km}\end{array}$} \\
\hline VIS & $400-490 \mathrm{~nm}$ & 1500 & $\mathrm{NO}_{2} ; \mathrm{O}_{2}-\mathrm{O}_{2}$ cloud fraction/pressure & \\
\hline NIR & $710-775 \mathrm{~nm}$ & $\begin{array}{l}\text { Absorption } 100 \\
\text { Continuum } 500\end{array}$ & $\begin{array}{l}\text { Cloud optical thickness/ pressure / } \\
\text { fraction; aerosol height distribution, } \\
\mathrm{H}_{2} \mathrm{O}\end{array}$ & \\
\hline SWIR & $2314-2375 \mathrm{~nm}$ & $\begin{array}{l}950 \text { (bright) } \\
200 \text { (dark) }\end{array}$ & $\mathrm{CO}, \mathrm{CH}_{4}$ & $\begin{array}{l}\text { Spectral resolution: } 0.25 \mathrm{~nm} \\
\text { Spectral sampling: } 0.125 \mathrm{~nm} \\
\text { Swath: } 2600 \mathrm{~km} / 114^{\circ} \\
\text { Spatial sampling: } 8 \mathrm{~km}\end{array}$ \\
\hline
\end{tabular}

Table 4 TROPOMI key parameters. The UV1 channel is meant for measurements of the stratosphere and upper troposphere and has relaxed spatial and spectral requirements. The $\mathrm{S} / \mathrm{N}$ values are for small solar zenith angles and low surface albedo. This corresponds to the minimum scenario, in which in the absorption structures have a small amplitude.

For the other channels, we see a spectral resolution about equal to the OMI and SCIAMACHY values and the spatial resolution of $8 \mathrm{~km}$, at nadir. In combination with the fairly high signal-to-noise requirements and the fact that these requirements have to be met for very low albedo spectra (albedo 0.02), this is a very stringent requirement although it is not applicable to the SWIR channel.

To explain the challenge, we have to consider the limiting factor for signal-to-noise, the amount of photons which are captured in a detector pixel. This amount or the enery per pixel is as follows.

$$
E=I . T \cdot t_{\mathrm{exp}} \cdot E t \cdot Q E \cdot d \lambda
$$

Where

$\begin{array}{ll}\text { E } & \text { energy per pixel (photons) } \\ \mathrm{I} & \left.\text { Radiance (photons/(s.nm. } \mathrm{cm}^{2} . \mathrm{sr}\right) \\ \mathrm{t}_{\mathrm{exp}} & \text { Exposure time }(\mathrm{s}) \\ \mathrm{Et} & \text { Etendue }\left(\mathrm{sr} . \mathrm{cm}^{2}\right) \\ \mathrm{QE} & \text { quantum efficiency }(.) \\ \mathrm{d} \lambda & \text { wavelength sampling distance }(\mathrm{nm})\end{array}$

And where the etendue Et is expressed as follows.

$$
E t=S . \Omega
$$

Where

$\mathrm{S} \quad$ energy capturing area $\left(\mathrm{cm}^{2)}\right.$

$\Omega \quad$ space angle (sr)

Via energy conservation the expression for etendue is valid both at the telescope and at the detector side. This leads to the conclusion that the most significant means to increase the energy per pixel is via the detector pixel area ( $\mathrm{S}$ on the detector side) and this has the clear disadvantage of being related to the instrument size, via focal lengths and beam diameters.

This has lead to the following approach.

- We firstly have to take care that the other parameters in the expression for $\mathrm{E}$ are reasonably close to maximum; as compared to the OMI on AURA this means that additional apertures in the UV2 and Visible channels are to be removed and that the low pass coating on the secundary telescope mirror has to be replaced by a regularly efficient coating

- Next we perform trade-offs between the instrument envelope and the instrument requirements 
The last step includes the optical design and there we explore novel techniques to make the design compact. For the SWIR channel, an immersed Ge grating is used, allowing for a compact design (see budgets later on).

TROPOMI will use Si-based CMOS (Complementary Metal Oxide Semiconductor) detector technology. Compared to the frame-transfer CCDs employed in OMI-AURA, the CMOS detectors have better radiation hardness, require less offchip circuitry and consume less power. Each detector will have a 16 bit analogue-to-digital converter to have a digital interface to the ELM. The SWIR channel will use HgCdTe-based CMOS technology.

SCIAMACHY is after launch bothered by ice deposition on its SWIR detectors, leading to the need of periodical deicing. The effect originated from outside the instrument but for TROPOMI we want to take care that there is no such sensitivity to outside effects. This is firstly taken care of by the design of thermal blankets and secondly by the venting design. In OMI there is no such difficulty but we have changed the detector baseline to avoid the detector degradation effects that can be observed in OMI. These have lead to an adjustment in the procedures for including detector calibration data in the $\mathrm{o}-1 \mathrm{~b}$ processing chain.

TROPOMI consists of three modules: the separate Optical Assemblies (OA) for the UV-Visible-NIR and for the SWIR and an Electronics Module (ELM). The optical benches for the UV-Visible-NIR and for the SWIR have been separated because of the quite different thermal requirements: the first $\mathrm{OA}$ is operated close to room temperature with detectors cooled to typically $-40{ }^{\circ} \mathrm{C}$ and the SWIR OA is at $220 \mathrm{~K}$ en the detectors at $165 \mathrm{~K}$. The advantage of this approach is clearly that the thermal design can be optimized which allows both OA's to be cooled passively. The disadvantage is that separate telescopes have to be properly aligned in the AIT process but in view of the OMI and SCIAMACHY experience, the advantage of thermal flexibility is more important.

To accommodate the temperature gradients between bench and detectors a so-called labyrinth construction is used similar to the implementation in SCIAMACHY. The TROPOMI cold parts will be passively cooled.

An important element in the optical design is the polarization scrambler. Results from OMI-AURA demonstrate that this concept works very well and avoids the need for polarization measurement devices. The scramblers for TROPOMI have to be redesigned to optimize between spatial deterioration (diamond effect) and the scrambling performance which is less severe as compared to OMI because of the wider instrument internal beams.

In-orbit calibration is based on regular solar irradiance measurements using various types of diffusers. Like in OMIAURA, the optical design is optimized to minimize the differences in the light paths for radiance and irradiance measurements in the instrument. This aspect is important to cancel any remaining calibration errors and to minimize the impact of in-flight degradation. Other on-board calibration sources are light emitting diodes near each detector and a white light source.

The ELM provides an interface to the satellite bus and serves to control the detector readout, heaters and mechanisms, handle the video and thermistor data and provide power to the optical benches. The ELM is a high-density box in terms of power consumption and is operated at about $310-315 \mathrm{~K}$. Therefore it will be located at some distance from the optical benches.

The volume of the UV-Visible-NIR OA and ELM is $0.14 \mathrm{~m}^{3}$ and the target mass is $95 \mathrm{~kg}$, of which $0.04 \mathrm{~m}^{3}$ and $20 \mathrm{~kg}$ are allocated to the ELM. The power consumption ranges between $90 \mathrm{~W}$ (nominal) and $150 \mathrm{~W}$ (peak and decontamination mode). The SWIR OA has a mass of $36 \mathrm{~kg}$, a volume of $0.04 \mathrm{~m}^{3}$ and a power consumption between $15 \mathrm{~W}$ (nominal) and $70 \mathrm{~W}$ (peak). The total TROPOMI then amounts to $131 \mathrm{~kg}$.

\section{REFERENCES}

1. Levelt et al, IEEE Trans. Geo. Rem. Sens. Aura Special Issues, 2005

2. Krijger et al, private communication, 2005

3. CAMEO proposal: http://mls.jpl.nasa.gov/joe/CAMEO_mission_concept.pdf 